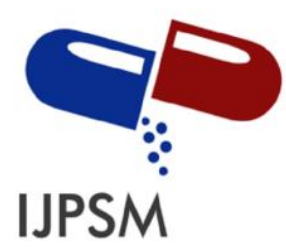

Saloni Chourasia et al, Int. Journal of Pharmaceutical Sciences and Medicine (IJPSM),

Vol.6 Issue. 8, August- 2021, pg. 42-72

ISSN: 2519-9889

Impact Factor: 3.426

\title{
Celiac Disease
}

\section{Saloni Chourasia; Sakshi Ahirwar \\ Swami Vivekanand College of Pharmacy \\ DOI: 10.47760/ijpsm.2021.v06i08.004}

\begin{abstract}
Celiac disease is an autoimmune disorder in which our immune system responds abnormally to gluten. Where symptoms of celiac disease diarrhea, bloating, fatigue, low blood count and osteoporosis. Many have no symptoms. Treatment of celiac disease is permanently removing gluten from our diet.
\end{abstract}

Keywords: Celiac disease, Endoscopy, biopsy, Colonscopy, Gluten effect.

\section{INTRODUCTION}

\section{Celiac Disease}

Celiac disease is a serious autoimmune disorder that can occur in genetically predisposed people where the ingestion of gluten leads to damage in the small intestine. It is estimated to affect 1 in 100 people worldwide. Two and one-half million Americans are undiagnosed and are at risk for long-term health complications.

When people with celiac disease eat gluten (a protein found in wheat, rye and barley), their body mounts an immune response that attacks the small intestine. These attacks lead to damage on the villi, small finger like projections that line the small intestine, that promote nutrient absorption. When the villi get damaged, nutrients cannot be absorbed properly into the body.

\section{Celiac disease is hereditary, meaning that it runs in families.}

People with a first-degree relative with celiac disease (parent, child, sibling) have a 10 risk of developing Celiac Disease. 


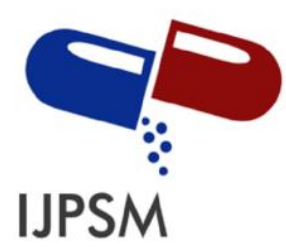

Saloni Chourasia et al, Int. Journal of Pharmaceutical Sciences and Medicine (IJPSM), Vol.6 Issue. 8, August- 2021, pg. 42-72

ISSN: 2519-9889

Impact Factor: 3.426

\section{CELIAC Disease}

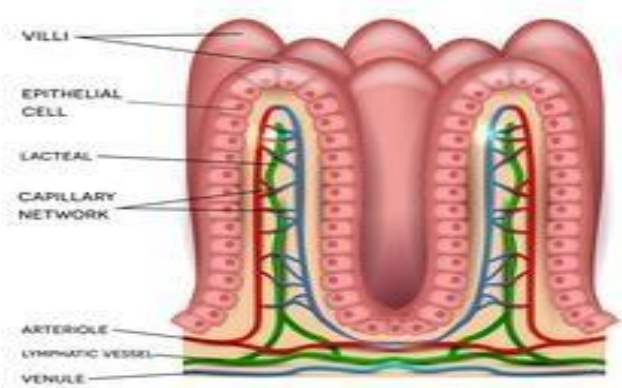

NORMAL VILLI

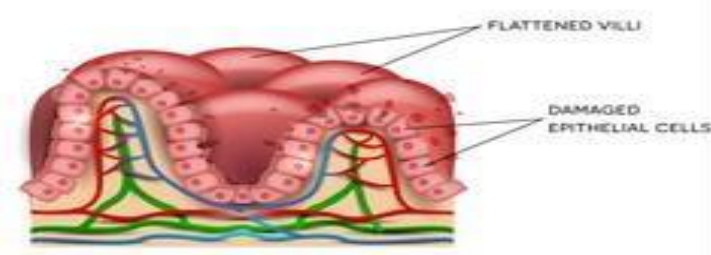

DAMAGED VILLI

Figure: 1 Celiac Disease

\section{Symptoms of Celiac Disease}

Celiac disease can be difficult to diagnose because it affects people differently. There are more than 200 known celiac disease symptoms which may occur in the digestive system or other parts of the body. Some people develop celiac disease as a child, others as an adult. The reason for this is still unknown.

Some people with celiac disease have no symptoms at all, but still test positive on the celiac disease blood test. A few others may have a negative blood test, but have a positive intestinal biopsy. However, all people with celiac disease are at risk for long-term complications, whether or not they display any symptom. 


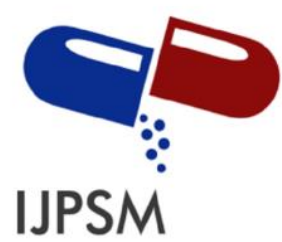

Saloni Chourasia et al, Int. Journal of Pharmaceutical Sciences and Medicine (IJPSM), Vol.6 Issue. 8, August- 2021, pg. 42-72

ISSN: 2519-9889

Impact Factor: 3.426

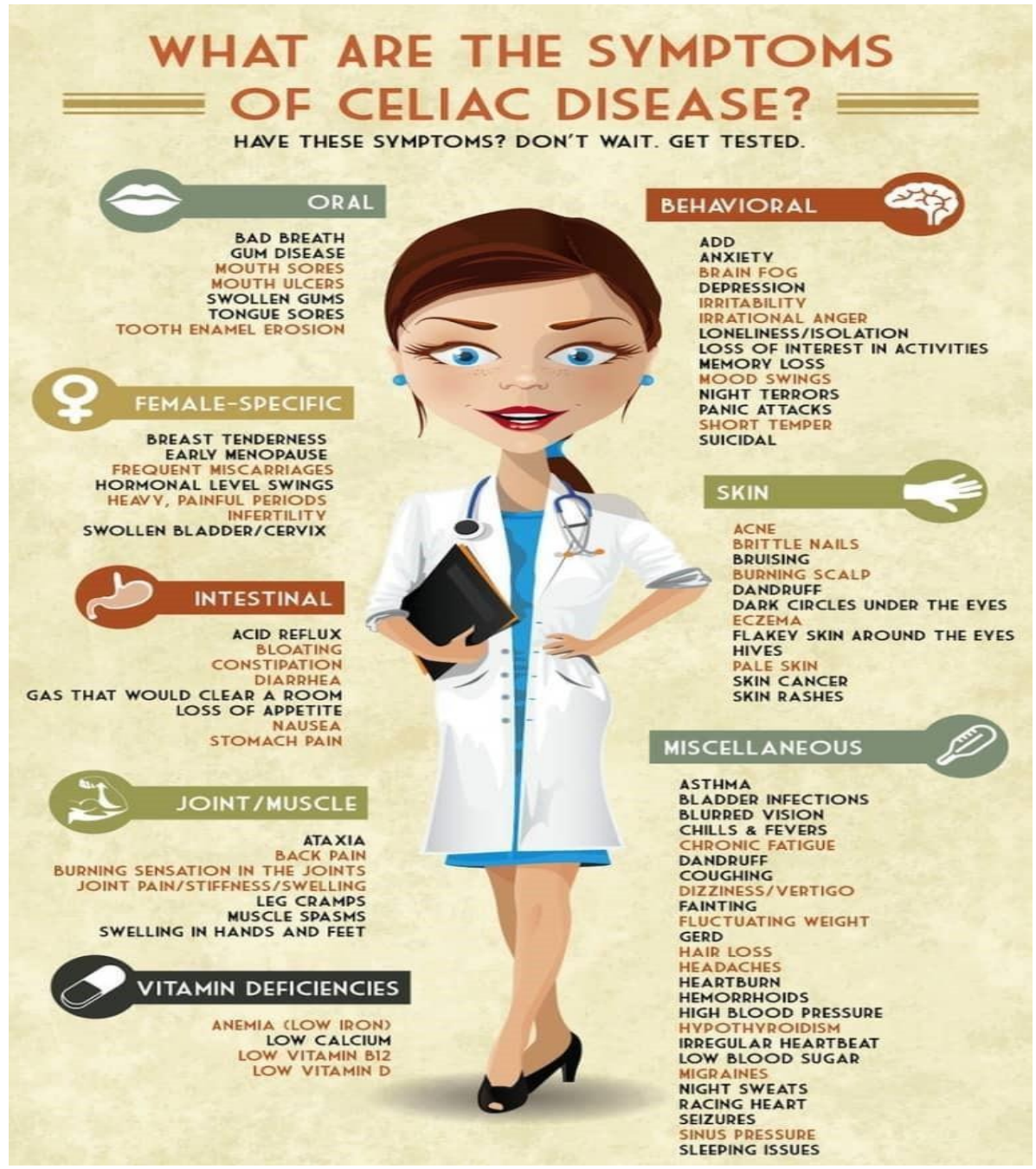

Figure:2 Symptoms of celiac disease

Celiac disease symptoms typically include:

- Bloating

- Cramping and abdominal pain

- Diarrhea or constipation

- Trouble concentrating or 'brain fog'

- Changes in weight

- Sleep disturbances including insomnia

- Chronic fatigue or lethargy

- Nutrient deficiencies (malnutrition)

- Chronic headaches

- Joint or bone pains 


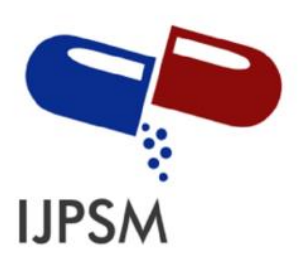

Saloni Chourasia et al, Int. Journal of Pharmaceutical Sciences and Medicine (IJPSM), Vol.6 Issue. 8, August- 2021, pg. 42-72

ISSN: 2519-9889

Impact Factor: 3.426

- Changes in mood, such an anxiety

- Tingling numbness in the hands and feet

- Seizures

- Irregular periods, infertility or recurrent miscarriage

- Canker sores inside the mouth

- Thinning hair and dull skin

\section{IF Your Child Have Celiac Disease}

Digestive symptoms are more common in infants and children. Here are the most common symptoms found in children:

- Abdominal bloating and pain

- Chronic diarrhoea

- Vomiting

- Constipation

- Pale, foul-smelling, or fatty stool

- Weight loss

- Fatigue

- Irritability and behavioural issues

- Dental enamel defects of the permanent teeth

- Delayed growth and puberty

- Short stature

- Failure to thrive

- Attention Deficit Hyperactivity Disorder (ADHD)

\section{IF You Have Celiac Disease:}

Adults are less likely to have digestive symptoms, with only one-third experiencing diarrhoea. Adults are more likely to have:

- Unexplained iron-deficiency aneamia

- Fatigue

- Bone or joint pain

- Arthritis

- Osteoporosis or osteopenia (bone loss)

- Liver and biliary tract disorders (transaminitis, fatty liver, primary sclerosing cholangitis, etc.)

- Depression or anxiety

- Peripheral neuropathy (tingling, numbness or pain in the hands and feet)

- Seizures or migraines

- Missed menstrual periods

- Infertility or recurrent miscarriage

- Canker sores inside the mouth

- Dermatitis herpetiformis (itchy skin rash) 


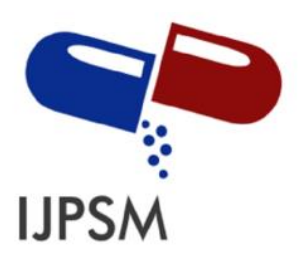

Saloni Chourasia et al, Int. Journal of Pharmaceutical Sciences and Medicine (IJPSM), Vol.6 Issue. 8, August- 2021, pg. 42-72

ISSN: 2519-9889

Impact Factor: 3.426

\section{Celiac Disease Affects the Digestive System}

When celiac disease symptoms increase, it's a result of gluten kicking off inflammatory responses that are tied to dysfunction mostly within the digestive, endocrine and central nervous systems. Much of the problem begins in the gut, where a large percentage of the immune system is actually held. When someone with celiac disease consumes gluten, essentially an "alarm" is sounded within the gut environment that sends the immune system.

Exposure to the gliadin protein increases gut permeability, which means small tears (or junctions) in the gut lining can open wider and allow for substances to pass through and enter the bloodstream. The immune system responds by damaging or destroying villi, which are the tiny protrusions that line the small intestines. Normally in someone who is healthy, the gut wall does a great job of keeping particles from emptying into the bloodstream, but irritations caused by food sensitives causes this system to break down.

This process is known as "leakv gut svndrome," and when you develop this condition you can become highly susceptible to other food allergies or sensitivities that you didn't previously have, due to the immune system working on overdrive to get things under control.

Gluten is also said to have certain "sticky" qualities that can interfere with proper absorption and digestion of important nutrients when people have a gluten intolerance, which leads to poorly digested food within the digestive tract, deficiencies and further inflammation. (8) When the immune system recognizes that foods aren't being properly broken down within the intestines, leaky gut syndrome symptoms can increase as the body continues to assault the lining of the small intestine, causing reactions like abdominal pain, nausea, diarrhea, constipation and intestinal distress.

Leaky gut syndrome makes it possible for lipopolysaccharides to dysfunction, which are structural components of our small microbial cells that live within our guts. When these are able to penetrate the gut lining by sneaking through small openings in the gut wall, they increase systemic inflammation. 


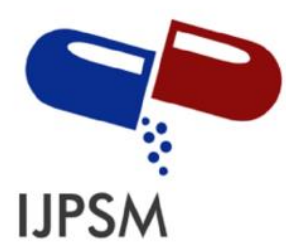

Saloni Chourasia et al, Int. Journal of Pharmaceutical Sciences and Medicine (IJPSM), Vol.6 Issue. 8, August- 2021, pg. 42-72

ISSN: 2519-9889

Impact Factor: 3.426

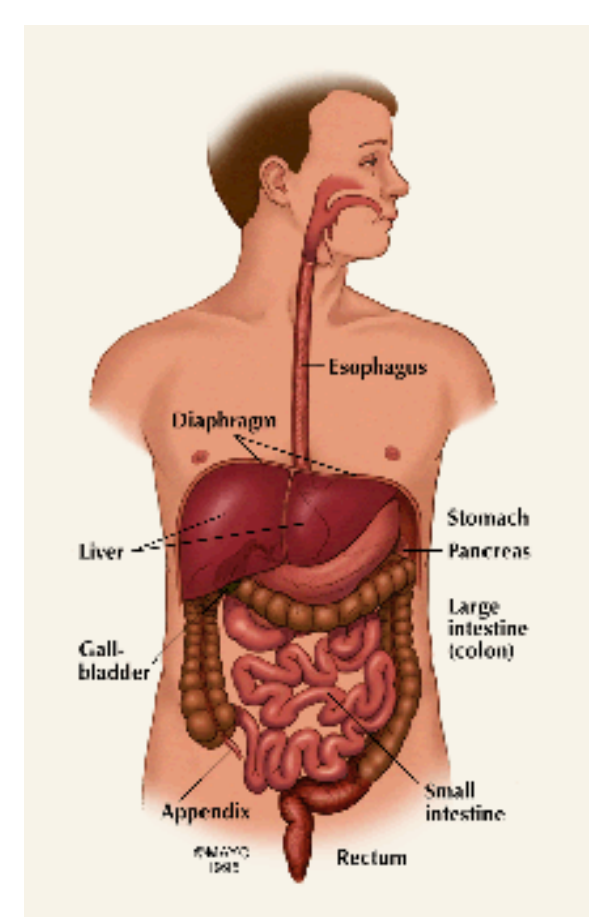

Figure:3 Digestive Tract

\section{Population affected by Celiac Disease}

Celiac disease affects $1 \%$ of healthy, average Americans. That means at least 3 million people in our country are living with celiac disease - $97 \%$ of them are undiagnosed. Type 1 Diabetes affects 3 million people; $6 \%$ (180,000) of those diagnosed also have celiac disease.

\section{Percentage of the population has celiac disease}

The disease, genetic in origin, affects a reported three million Americans (one percent of the population). Although 20-30 percent of the world's population has been found to carry the HLA-DQ gene associated with a genetic susceptibility to celiac disease, 95 percent of celiacs still go undiagnosed.

About 1 in 100 people - about 1 percent - have celiac disease, an inherited autoimmune disease that causes damage to the small intestine when gluten is ingested. About .4 percent of people have a doctor-diagnosed wheat allergy.

\section{Classical, Non-classical and Silent Celiac Disease}

According to the World Gastroenterology Organization, celiac disease may be divided into two 


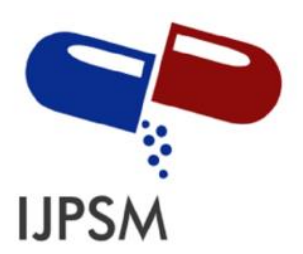

Saloni Chourasia et al, Int. Journal of Pharmaceutical Sciences and Medicine (IJPSM), Vol.6 Issue. 8, August- 2021, pg. 42-72

ISSN: 2519-9889

Impact Factor: 3.426

types: classical and non-classical.

In classical celiac disease, patients have signs and symptoms of malabsorption, including diarrhoea, steatorrhea (pale, foul-smelling, fatty stools), and weight loss or growth failure in children.

In non-classical celiac disease, patients may have mild gastrointestinal symptoms without clear signs of malabsorption or may have seemingly unrelated symptoms. They may suffer from abdominal distension and pain, and/or other symptoms such as: iron-deficiency anemia, chronic fatigue, chronic migraine, peripheral neuropathy (tingling, numbness or pain in hands or feet), unexplained chronic hypertransaminasemia (elevated liver enzymes), reduced bone mass and bone fractures, and vitamin deficiency (folic acid and B12), late menarche/early menopause and unexplained infertility, dental enamel defects, depression and anxiety, dermatitis herpetiformis (itchy skin rash), etc.

Silent celiac disease is also known as asymptomatic celiac disease. Patients do not complain of any symptoms, but still experience villous atrophy damage to their small intestine. Studies show that even though patients thought they had no symptoms, after going on a strict gluten- free diet they report better health and a reduction in acid reflux, abdominal bloating and distention and flatulence.

First-degree relatives (parents, siblings, children), whether or not experiencing symptoms, should always be screened, since there is a 1 in 10 risk of developing celiac disease.

The number of ways celiac disease can affect patients, combined with a lack of training in medical schools and primary care residency programs, contributes to the poor diagnosis rate in the United States. Currently it is estimated that $80 \%$ of the celiac disease population remains undiagnosed.

\section{Screening \& Diagnosis}

There are two steps to finding out if you have celiac disease: screening and diagnosis. You should always consult with a physician experienced with celiac disease to ensure proper diagnosis.

\section{Screening}

A simple blood test is available to screen for celiac disease. People with celiac disease who eat gluten have higher than normal levels of certain antibodies in their blood. These antibodies are produced by the immune system because it views gluten (the proteins found in wheat, rye and barley) as a threat. You must be on a gluten-containing diet for antibody (blood) testing to be accurate.

\section{Who should get screened?}

1. Children older than 3 and adults experiencing symptoms of celiac disease

2. First-degree relatives of people with celiac disease - parents, siblings and children have a 1 in (C) 2021, IJPSM All Rights Reserved, www.ijpsm.com 


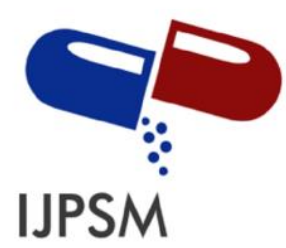

Saloni Chourasia et al, Int. Journal of Pharmaceutical Sciences and Medicine (IJPSM), Vol.6 Issue. 8, August- 2021, pg. 42-72

ISSN: 2519-9889

Impact Factor: 3.426

10 risk compared to 1 in 100 in the general population

3. Any individual with an associated autoimmune disorder or other condition, especially type 1 diabetes mellitus, autoimmune thyroid disease, autoimmune liver disease, Down syndrome, Turner syndrome, Williams syndrome, and selective immunoglobulin A (IgA) deficiency

\section{Screening for Celiac Disease in Children Under the Age of 3 TheFirstStep:tTG-IgA Test}

For most children and adults, the best way to screen for celiac disease is with the Tissue Transglutaminase IgA antibody, plus an IgA antibody in order to ensure that the patient generates enough of this antibody to render the celiac disease test accurate.

For young children (around age 2 years or below), Deamidated Gliadin Ig A and IgG antibodies should also be included. All celiac disease blood tests require that you be on a gluten-containing diet to be accurate. Tissue Transglutaminase Antibodies (tTG-IgA) - The tTG-IgA test will be positive in about $98 \%$ of patients with celiac disease who are on a gluten-containing diet. This is called the test's sensitivity. The same test will come back negative in about $95 \%$ of healthy people without celiac disease. This is called the test's specificity. Though rare, this means patients with celiac disease could have a negative antibody test result.There is also a slight risk of a false positive test result, especially for people with associated autoimmune disorders like type 1 diabetes, autoimmune liver disease, Hashimoto's thyroiditis, psoriatic or rheumatoid arthritis, and heart failure, who do not have celiac disease.There are other antibody tests available to double-check for potential false positives or false negatives, but because of potential for false antibody test results, a biopsy of the small intestine is the only way to diagnose celiac disease.

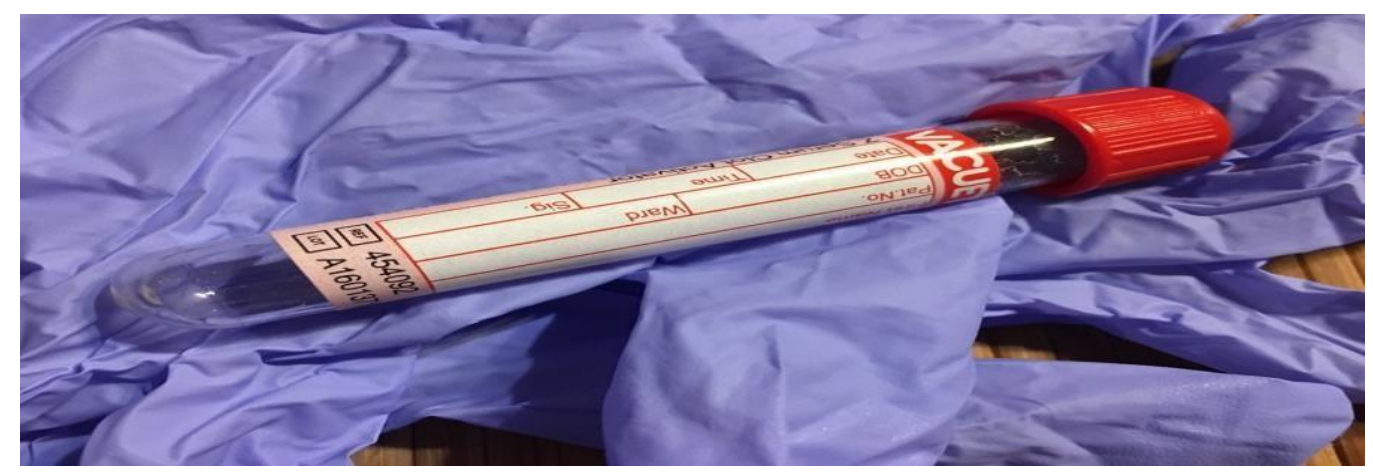

Figure:4 Test tube 


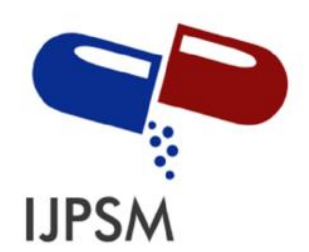

Saloni Chourasia et al, Int. Journal of Pharmaceutical Sciences and Medicine (IJPSM), Vol.6 Issue. 8, August- 2021, pg. 42-72

ISSN: 2519-9889

Impact Factor: 3.426

\section{Other Tests}

IgA Endomysial antibody (EMA): The EMA test has a specificity of almost $100 \%$, but is not as sensitive as the tTG-IgA test. About 5-10\% of people with celiac disease do not have a positive EMA test. It is also very expensive in comparison to the tTG-IgA and requires the use of primate esophagus or human umbilical cord. It is usually reserved for difficult to diagnose patients.

Total serum IgA: This test is used to check for IgA deficiency, a condition associated with celiac disease that can cause a false negative tTG-IgA or EMA result. If you are IgA deficient, your doctor can order a DGP or tTG-IgG test.

Deamidated gliadin peptide (DGP IgA and IgG): This test can be used to further screen for celiac disease in individuals with IgA deficiency or people who test negative for tTg or EMA antibodies.

While it is very rare, it is possible for someone with celiac disease to have negative antibody test results. If your tests were negative, but you continue to experience symptoms, consult your physician and undergo further medical evaluation.

\section{The Gluten Challenge}

If you are currently on a gluten-free diet, your physician may recommend a gluten challenge to allow antibodies to build in your bloodstream prior to testing. The recommended gluten intake for the gluten challenge is two slices of wheat-based bread for 6-8 weeks. A gluten challenge should only be supervised by a physician trained in celiac disease, who can move you immediately to a biopsy if your symptoms are severe.

\section{Never undertake a gluten challenge when pregnant.}

\section{Genetic Testing}

People with celiac disease carry one or both of the HLA DQ2 and DQ8 genes, but so does up to $25-30 \%$ of the general population. Carrying HLA DQ2 and/or DQ8 is not a diagnosis of celiac disease nor does it mean you will ever develop celiac disease. However, if you carry HLA DQ2 and/or DQ8, your risk of developing celiac disease is 3\% instead of the general population risk of $1 \%$.

Since celiac disease is genetic, this means it runs in families. First-degree family members (parents, siblings, children), who have the same genotype as the family member with celiac disease, have up to a $40 \%$ risk of developing celiac disease. The overall risk of developing celiac disease when the genotype is unknown is $7 \%$ to $20 \%$. A negative gene test excludes the possibility of later developing celiac disease, so this can be valuable information for first- 


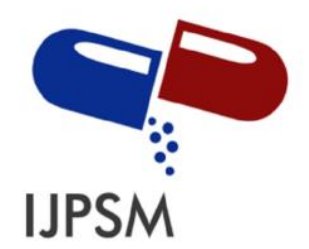

Saloni Chourasia et al, Int. Journal of Pharmaceutical Sciences and Medicine (IJPSM), Vol.6 Issue. 8, August- 2021, pg. 42-72

ISSN: 2519-9889

Impact Factor: 3.426

degree family members. We recommend performing the genetic test for celiac disease in family members, especially children, to prevent future unnecessary screening. We recommend screening gene-positive first-degree relatives every 3- 5 years.

\section{Who should have Celiac HLA testing?}

Those on a gluten-free diet - celiac antibody blood testing is not accurate

- when diagnosis of celiac disease is not clear

- ambiguous antibody testing results (especially in children under the age of 3)

- equivocal intestinal biopsy results

- discrepancy between antibody and biopsy findings Family members of people with celiac disease to evaluate risk

- a negative result assures a 99\% probability that the family member will NOT develop celiac disease

- a positive result indicates the family member should follow up with celiac antibody testing every 2-3 years or immediately if symptoms develop

\section{How do I get tested?}

Your physician should be able to order genetic testing. Genetic testing can be done by blood test, saliva test or cheek swab. Genetic testing is expensive with the cost running in the hundreds of dollars, but may be covered by some insurance plans. First-degree family members unsure about the expense should weigh this against the time and expense of undergoing life-time serologic testing.

\section{Diagnosis}

The only way to confirm a celiac disease diagnosis is to have an intestinal biopsy. A pathologist will assign a Modified Marsh Type to the biopsy findings. A Type of 3 indicates symptomatic celiac disease. However, Types 1 and 2 may also indicate celiac disease. 


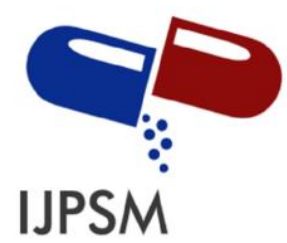

Saloni Chourasia et al, Int. Journal of Pharmaceutical Sciences and Medicine (IJPSM), Vol.6 Issue. 8, August- 2021, pg. 42-72

ISSN: 2519-9889

Impact Factor: 3.426

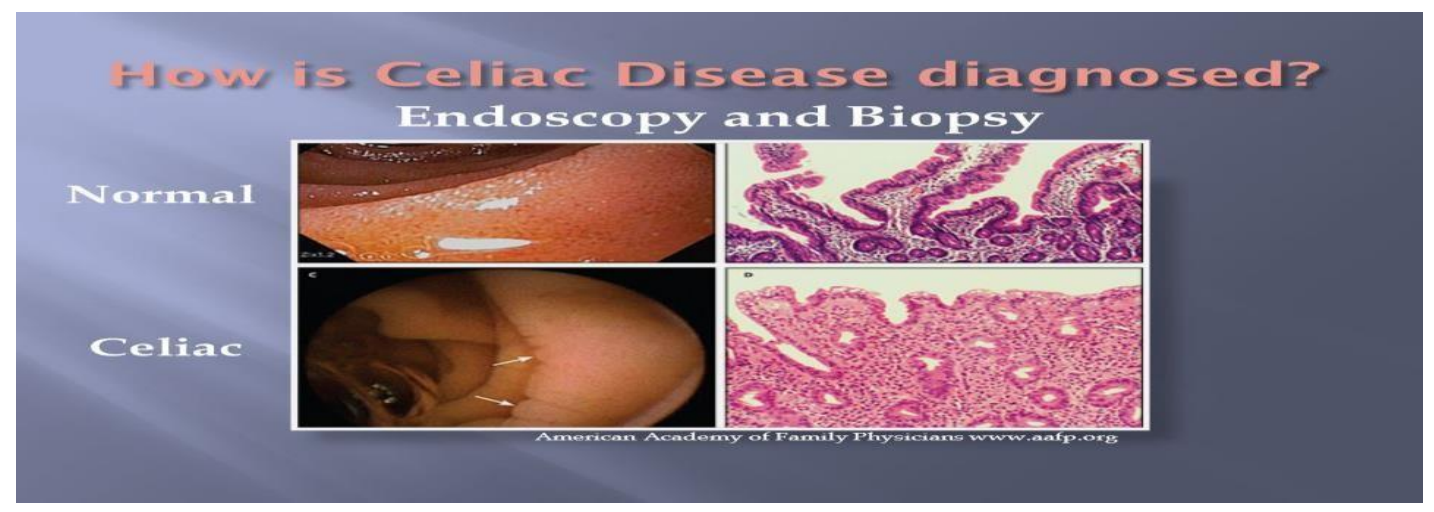

Figure:5 Endoscopy and Biopsy

\section{Why an Intestinal Biopsy?}

An intestinal (duodenal) biopsy is considered the "gold standard" for diagnosis because it will tell you (1) if you have celiac disease, (2) if your symptoms improve on a gluten-free diet due to a placebo effect (you feel better because you think you should) or (3) if you have a different gastrointestinal disorder or sensitivity which responds to change in your diet. If the results of the antibody or genetic screening tests are positive, your doctor may suggest an endoscopic biopsy of your small intestine. An endoscopy is a procedure that allows your physician to see what is going on inside your GI tract. A scope is inserted through the mouth and down the esophagus, stomach and small intestine, giving the physician a clear view and the option of taking a sample of the tissue. This is usually an outpatient procedure. Samples of the lining of the small intestine will be studied under a microscope to look for damage and inflammation due to celiac disease. It is recommended that the doctor take at least 4-6 duodenal samples from the second part of duodenum and the duodenal bulb, in order to obtain an accurate diagnosis.

\section{What Does the Intestinal Biopsy Show? (Give Me the Science)}

- Density of intra-epithelial lymphocytes (IELs), which are white blood cells found in the immune system. More than 25 IELs per 100 epithelial cells is significant. Epithelial cells line your intestines and act as a barrier between the inside and the outside of your body.

- Crypt hyperplasia with a decreased villi/crypt ration. Crypts are grooves between the villi, which are the small fingerlike projections that line the small intestine and promote nutrient absorption. Crypt hyperplasia is when the grooves are elongated compared to a normal intestinal lining which has short crypts. 


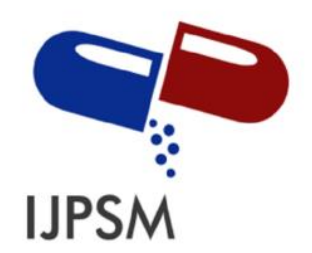

Saloni Chourasia et al, Int. Journal of Pharmaceutical Sciences and Medicine (IJPSM), Vol.6 Issue. 8, August- 2021, pg. 42-72

ISSN: 2519-9889

Impact Factor: 3.426

- Blunted or atrophic villi. This is a shrinking and flattening of the villi due to repeated gluten exposure.

- Mononuclear cell infiltration in the lamina propria. The lamina propria is a thin layer of loose connective tissue, which together with the epithelium forms the mucosa which stops pathogens from entering the body.

- Epithelial changes, including structural abnormalities in epithelial cells.

The endoscopy itself may show scalloping and/or flattening of dudodenal folds, fissuring over the folds, and a mosaic pattern of mucosa of folds.

\section{Modified Marsh Classification of Histologic Findings in Celiac Disease}

The World Gastroenterology Organization recommends pathologists use a modified Marsh classification for interpretation. Dr. Michael Marsh introduced the classification system in 1992 to describe the stages of damage in the small intestine as seen under a microscope, also known as histological changes. Originally the Marsh Types ranged from 0 to 4, with a type of 3 indicating celiac disease. It has since been simplified to allow for a greater degree of consistency and reproducibility between pathologists.

\begin{tabular}{|c|c|c|c|c|}
\hline \multicolumn{5}{|c|}{ Modified Marsh Classification of histologic findings in celiac disease (Oberhuber) } \\
\hline $\begin{array}{c}\text { Marsh } \\
\text { Type }\end{array}$ & $\begin{array}{c}\text { IEL/100 } \\
\text { enterocytes- } \\
\text { jejunum* }\end{array}$ & \begin{tabular}{|c|} 
IEL / 100 \\
enterocytes \\
- duodenum*
\end{tabular} & \begin{tabular}{|c|} 
Crypt \\
hyperplasia
\end{tabular} & Villi \\
\hline 0 & $<40$ & $<30$ & Normal & Normal \\
\hline 1 & $>40$ & $>30$ & Normal & Normal \\
\hline 2 & $>40$ & $>30$ & Increased & Normal \\
\hline $3 \mathrm{a}$ & $>40$ & $>30$ & Increased & Mild atrophy \\
\hline $3 b$ & $>40$ & $>30$ & Increased & $\begin{array}{l}\text { Marked } \\
\text { atrophy }\end{array}$ \\
\hline $3 c$ & $>40$ & $>30$ & Increased & $\begin{array}{l}\text { Complete } \\
\text { atrophy }\end{array}$ \\
\hline
\end{tabular}

\section{*IEL/100 enterocytes - intra-epithelial lymphocytes (IELS) per 100 enterocytes (epithelial cells in the small intestine)}

- Type 0: Intestinal lining is normal -celiac disease highly unlikely

- Type 1: Intestinal lining has been infiltrated with IELS - seen in patients on a gluten free diet (suggesting minimal amounts of gluten or gliadin are being ingested), patients with dermatitis herpetiformis and family members of celiac disease patients. This may also indicate 


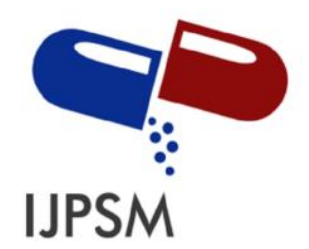

Saloni Chourasia et al, Int. Journal of Pharmaceutical Sciences and Medicine (IJPSM), Vol.6 Issue. 8, August- 2021, pg. 42-72

ISSN: 2519-9889

Impact Factor: 3.426

gastroduodenits caused by $\mathrm{H}$. pylori, hypersensitvity to food, infectons (viral, parasitc, bacterial), bacterial overgrowth, pharmacological drugs (mainly NSAIDs), IgA defcit, common variable immunodefciency or Crohn's disease.

- $\quad$ Type 2: Very rare, seen occasionally in dermatitis herpetiformis.

- Type 3: Spectrum of changes seen in symptomatic celiac disease

Simplified systems may be more reproducible (Corazza, Roberts, Ensari)

- Grade A/Type 1: increased intraepithelial lymphocytes but no villous atrophy

o Seen in patients on gluten free diet (suggesting minimal amounts of gluten or gliadin are being ingested); patients with dermatitis herpetiformis; family members of celiac disease patients, not specific, may be seen in infections

- Grade B1/Type 2: villi still present but shortened

- Spectrum of changes seen in symptomatic celiac disease

- Grade B2/Type 3: complete villous atrophy

- Spectrum of changes seen in symptomatic celiac disease

\section{What to Expect During an Endoscopy}

This procedure takes a little less than thirty minutes and, for adults, sedatives and local anesthetics are used. Children are usually put under general anesthesia. During the biopsy, the gastroenterologist will insert a small tube with a camera through the patient's mouth and into the digestive tract to the small intestine.

Once there, the physician will examine the duodenum (entryway into the small intestine) and take multiple tissue samples due to the "patchy" nature of villous atrophy. The tissue samples will then be examined by a pathologist under a microscope and assigned a Marsh classification.

Since there are no nerve endings in the lining of the intestine, the procedure is not painful though some patients may experience a sore throat.

Patients who cannot or will not tolerate an endoscopy may be given the option to undergo video capsule or "pill" endoscopy where a capsule the size of a large vitamin pill is swallowed and takes thousands of pictures of the small intestine. However, there is no conclusive evidence that this can substitute for traditional endoscopy and biopsy. 


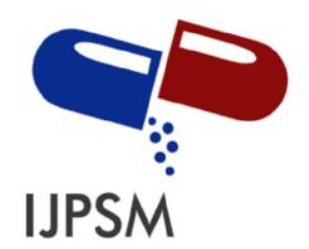

Saloni Chourasia et al, Int. Journal of Pharmaceutical Sciences and Medicine (IJPSM),

Vol.6 Issue. 8, August- 2021, pg. 42-72

ISSN: 2519-9889

Impact Factor: 3.426

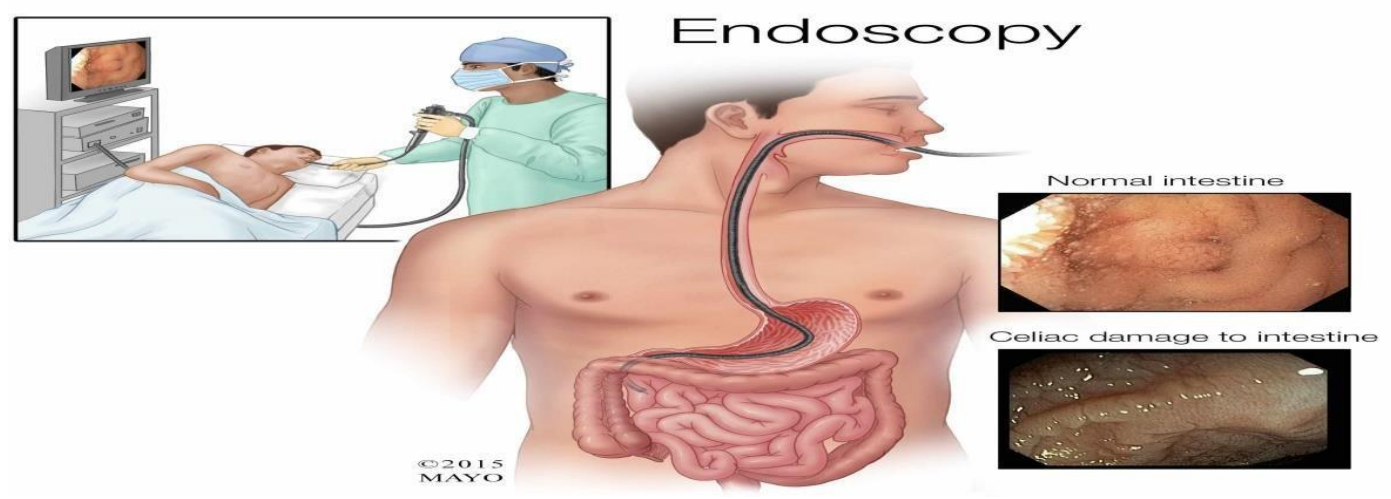

Figure:6 Endoscopy

\section{For Individuals with Dermatitis Herpetiformis (DH)}

A skin biopsy is sufficient for diagnosis of both DH and celiac disease.

This biopsy involves collecting a small piece of skin near the rash and testing it for the IgA antibody. It is not necessary to perform an endoscopic biopsy to establish the diagnosis of celiac disease in a patient with $\mathrm{DH}$; the skin biopsy is definitive.

\section{For Children}

For children with symptoms and signs of malabsorption, a very high tTG-IgA titer ( $>10$ time upper limit of normal), and a positive EMA (antiendomysial) in a second blood sample, some physicians may recommend avoiding endoscopic biopsy, and directly starting a gluten-free diet.

Others may recommend genetic testing for additional confirmation. Resolution of symptoms while on a gluten-free diet may be used to confirm the diagnosis.

\section{Treatment \& Follow-Up}

\section{Lifelong Adherence to the Gluten-Free Diet}

Celiac disease is a chronic autoimmune disease, which means that you cannot "grow out" of it. The treatment for both celiac disease and non-celiac gluten/wheat sensitivity is lifelong adherence to a strict gluten-free diet. Only food and beverage with a gluten content less than 20 parts per million (ppm) is allowed. 


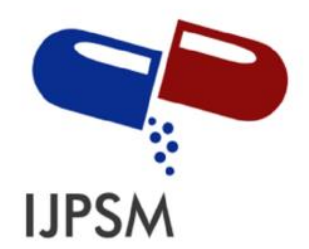

Saloni Chourasia et al, Int. Journal of Pharmaceutical Sciences and Medicine (IJPSM), Vol.6 Issue. 8, August- 2021, pg. 42-72

ISSN: 2519-9889

Impact Factor: 3.426

The gluten-free diet heals the villous atrophy in the small intestine, causing symptoms to resolve. Following the gluten-free diet also helps prevent future complications, including malignancies.

\section{Vitamins and Dietary Supplements}

Commonly, people with celiac disease are deficient in fiber, iron, calcium, magnesium, zinc, folate, niacin, riboflavin, vitamin B12, and vitamin D, as well as in calories and protein. Deficiencies in copper and vitamin B6 are also possible, but less common. After treatment with the gluten-free diet, most patients' small intestines recover and are able to properly absorb nutrients again.

However, patients may continue to be vitamin B deficient as the gluten-free diet may not provide sufficient supplementation. This can be remedied with a daily, gluten- free multivitamin. The multivitamin should not exceed $100 \%$ of the daily value (DV) for vitamins and minerals. Calcium and vitamin D supplementation may also be prescribed by your physician if your intake is not sufficient.

\section{Bone Health}

For adults, your physician should order a bone density test at time of diagnosis to test for osteopenia/osteoporosis (thin bones). A bone density test may also be ordered for children and adolescents who have experienced severe malabsorption, a prolonged delay in diagnosis, have bone disease symptoms or are non-compliant with the gluten-free diet.

If you are at high-risk for bone fracture, you will be prescribed dietary supplements and medication to correct this.

\section{Medication}

Medication is not normally required except in some cases of dermatitis herpetiformis, in which medication such as dapsone or sulfapyridine is administered for a short period of time to control the rash. In most individuals, following a strict gluten-free diet greatly reduces symptoms of dermatitis herpetiformis.

The true chances of getting a medication that contains gluten is extremely small, but as a protector of your health, you should eliminate all risks by evaluating the ingredients in your medications. 


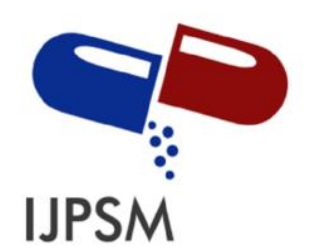

Saloni Chourasia et al, Int. Journal of Pharmaceutical Sciences and Medicine (IJPSM), Vol.6 Issue. 8, August- 2021, pg. 42-72

ISSN: 2519-9889

Impact Factor: 3.426

\section{Physician Follow-Up At Time of Diagnosis}

At time of diagnosis, your physician should:

- Perform a complete physical exam including determination of BMI and examinations for enlarged lymph nodes and occult blood in the stool

- For adults, and children with a long-delay in diagnosis, severe malabsorption or bone health isues, order bone densitometry

- Order celiac serology (anti-DGP IgA and anti-tTg IgA) and DQ2/DQ8 genetic testing, if not previously obtained

- Order routine tests (complete blood cell count, iron studies, vitamin B studies, thyroid functions tests with thyrotropin, liver enzymes, calcium, phosphate, 25-hydroxy vitamin D, copper, and zinc levels)

- Recommend family screening (DQ2/DQ8 genetic testing and celiac serology to include antitTg IgA, anti-DGP IgG, and total IgA to exlude IgA deficiency)

- Recommend a dietitian expert in celiac disease and the gluten-free diet to provide education and counseling

- Recommend a mental health professional to address the psychosocial aspects of going glutenfree and coping with a chronic disease, as needed

- Recommend a gluten-free multivitamin and additional supplementation as needed

- Assess hepatitis B, flu and pneumococcal immunization status

\section{3-6 Month Visit}

You should see your physician 3-6 months after your initial diagnosis and annually thereafter to identify nutritional deficiencies, address symptoms you may still be experiencing, and confirm your adherence to the gluten-free diet. Patients on a strict gluten-free diet should have a negative anti-tTg IgA test at the 6-12 month mark. At the 3-6 month visit, your physician should:

- Assess symptoms

- Perform a complete physical exam, on indication

- Order celiac serology (anti-DGP IgA and anti-tTg IgA)

- Repeat routine tests, if previously abnormal

\section{Month Visit}

At your 12 month visit, your anti-tTg IgA level should be as close to zero as possible. At this visit, your physician should:

- Assess symptoms

- Perform an abdominal physical examination, on indication

- Order celiac serology (anti-DGP IgA and anti-tTg IgA)

- Repeat routine tests

- Assess hepatitis B immunization status, if previously abnormal 


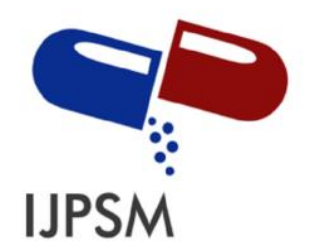

Saloni Chourasia et al, Int. Journal of Pharmaceutical Sciences and Medicine (IJPSM),

Vol.6 Issue. 8, August- 2021, pg. 42-72

ISSN: 2519-9889

Impact Factor: 3.426

\section{Annual Thereafter}

At your annual visit, your physician should:

- Assess symptoms

- Perform a complete physical exam

- Order celiac serology (anti-DGP IgA and anti-tTg IgA)

- Repeat routine tests

- Order other tests as clinically indicated

- Recommend a flu shot

- Recommend a dietitian to provide education and counseling as clinically indicated

- Recommend a mental health professional to address the psychosocial aspects of going glutenfree and coping with a chronic disease, as needed

- Repeat bone densitometry at 2-3 years, if previously abnormal, and for adolescents noncompliant with a gluten-free diet

- For adults, consider repeat small intestinal biopsy at 3-5 years to assess dietary compliance and rule-out refractory celiac disease

\section{Dietitian Follow-Up At Time of Diagnosis}

At time of diagnosis, your dietitian should:

- Provide gluten-free dietary counseling, including education on the inclusion of oats, crosscontamination, and label-reading for foods, medications and supplements

- Review nutritional needs including age-appropriate calcium and vitamin D intake

- Recommend a gluten-free multivitamin

\section{2-4 Week Visit}

At your 2 month visit, your dietitian should:

- Assess symptoms and coping skills

- Conduct a dietary review

\section{6-12 Month Visit}

At your 12 month visit, your dietitian should:

- Assess symptoms and coping skills

- Conduct a dietary review

\section{Month Visit}

If you are still symptomatic or are struggling with the gluten-free diet, your physician may refer you to dietitian for additional counseling and education. At this visit, your dietitian should: undiagnosed disease odyssey was worth sharing. In addition, some people with Celiac Disease also present with Addison's disease, which is a rare disease. 


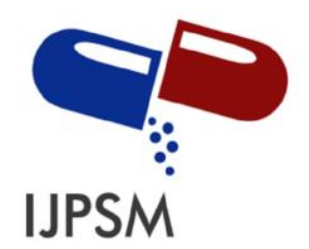

Saloni Chourasia et al, Int. Journal of Pharmaceutical Sciences and Medicine (IJPSM), Vol.6 Issue. 8, August- 2021, pg. 42-72

ISSN: 2519-9889

Impact Factor: 3.426

\section{\{CASE STUDY $\}$ Cheryl's Story}

My name is Cheryl, I am 30 years old and I have Celiac Disease. I went 25 years before I was finally diagnosed. I was always sick growing up. I missed a lot of school due to vomiting, stomach and intestinal pain. My abdomen was always bloated. It was almost as if I had a permanent cold virus. I got a lot of cold sores. I couldn't sit in the sun as I would get badly burned and develop a rash. My Mother used to tell the doctor that when I was sick, that dry toast would make me worse. The doctor said that bread could not hurt me.

By the time I was 24, I could no longer work. I had bleeding ulcers. I was in extreme pain 24 hours a day. I was vomiting every time I had anything to eat or drink. I had peripheral neuropathy due to my vitamin deficiencies. When a bed sheet would touch my ankle or calves, I would scream from the intense pain. I was off work for a whole year.

I went to the doctors every week and they always said the same thing, "we will give you a pregnancy test," they always came back negative. Then they would tell me I had the flu. Then one week the doctors were all booked up so I had a chance to see the head nurse practitioner in the clinic. After many questions, she thought I had Celiac Disease and sent me to the gastroenterologist. He gave me an endoscopy and later diagnosed me.

I have some permanent nerve damage, my lower right leg has been numb for 12 years and I am hyper-sensitive to cold. Now that I have been on a gluten free diet for almost 6 years, I feel great. I never knew what it felt like to not feel sick or be in pain.

\section{Celiac Disease in Children}

Celiac Disease Foundation Medical Advisory Board Member and Medical Director of the Program for Pediatric Inflammatory Bowel Diseases at Children's Hospital Colorado, discusses celiac disease in children and adolescents

Celiac disease may develop any time after wheat or other gluten containing foods are introduced into the diet, typically after 6-9 months of age. It is unknown why some children become ill early in life and others fall ill only after years of exposure. It is very important to test your child at the very first signs, or if celiac disease runs in your family. First-degree relatives (parent, sibling, child) have a 1 in 10 chance of developing celiac disease themselves. There is wide variation in the severity of symptoms - many children will experience symptoms within minutes to hours after consuming gluten, which may only last a few hours. In others, symptoms may last several days, or up to two weeks. Many children have mild symptoms that are easy to miss, such as having excessive gas, abdominal pain, or constipation. 


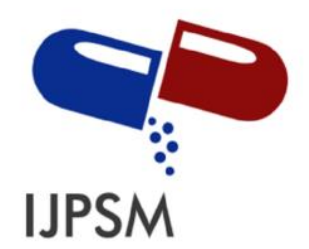

Saloni Chourasia et al, Int. Journal of Pharmaceutical Sciences and Medicine (IJPSM),

Vol.6 Issue. 8, August- 2021, pg. 42-72

ISSN: 2519-9889

Impact Factor: 3.426

Other children have more severe symptoms that can result in an earlier diagnosis, including failure to thrive, weight loss, and vomiting.Fortunately, children and adolescents typically respond well to treatment with the gluten-free diet. Most children feel significantly better after two weeks on the diet and attain normal height, weight, and bone health.

\section{Celiac disease affects children in different ways, depending on their age Infants and Toddlers}

Infants and toddlers tend to have more obvious symptoms which usually manifest in the gastrointestinal tract. Symptoms include, but are not limited to:

- Vomiting

- Bloating

- Irritability

- Poor growth

- Abdominal distention

- Diarrhea with very foul stools

- Malnutrition

\section{School-Age Children}

Vomiting is less common in school-age children than in infants and toddlers. Symptoms include, but are not limited to:

- Stomach aches or abdominal pain

- Abdominal distention

- Diarrhea

- Constipation

- Trouble gaining weight or weight loss

\section{Older Children and Teens}

Older children and teenagers may have symptoms or concerning signs that are not obviously related to the intestinal tract, which are called "extra intestinal" or "atypical" symptoms.

These symptoms are what may convince a physician to test for celiac disease. Some of these manifestations include:

- Stunted growth

- Weight loss

- Delayed puberty

- Achy pain in the bones or joints

- Chronic fatigue

- Recurrent headaches or migraines

- Itchy skin rash (dermatitis herpetiformis) 


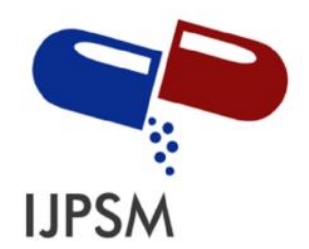

Saloni Chourasia et al, Int. Journal of Pharmaceutical Sciences and Medicine (IJPSM),

Vol.6 Issue. 8, August- 2021, pg. 42-72

ISSN: 2519-9889

Impact Factor: 3.426

- Recurring mouth sores, called aphthous ulcers, which look like canker sores

Adolescents with celiac disease may also have mood disorders, including anxiety and depression, as well as panic attacks.

\section{Celiac Disease in Children with No or Mild Symptoms}

There are two primary ways that celiac disease can be found in children without symptoms of concern. The first is to have an associated condition in which testing for celiac disease is recommended:

- Family member with celiac disease

- Type 1 diabetes

- Thyroid disease

- IgA deficiency

- Juvenile Chronic Arthritis

- Down syndrome (Trisomy 21)

- Williams syndrome

- Turner syndrome

The second is to have other signs of celiac disease that do not cause typical symptoms:

- Iron deficiency anemia

- High levels of liver enzymes AST and ALT

- Osteopenia (thin bones)

- Dental enamel defects

\section{Severe Celiac Disease in Children}

Severe cases of celiac disease in childhood are now very rare. Symptoms of severe cases include:

- Very low blood pressure

- Excessive water loss in stool, leading to "electrolyte disturbance"

- Abdominal obstruction called "intussusception"

\section{A typical adult celiac disease: Report of cases and review of the literature Case 1}

A 42-year-old Saudi male was presented to us with two years history of excessive hair fall and flatulence with recent worsening of his symptoms for further investigations and management. Additional history revealed weight loss of $10 \mathrm{~kg}$ in the last two years and occasional episodes of diarrhea without blood or mucous. He was diagnosed as having IBS and managed accordingly. The clinical examination revealed thin, pale and ill-looking patient with sunken 


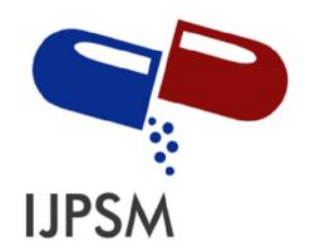

Saloni Chourasia et al, Int. Journal of Pharmaceutical Sciences and Medicine (IJPSM), Vol.6 Issue. 8, August- 2021, pg. 42-72

ISSN: 2519-9889

Impact Factor: 3.426

eyes, scanty hair, angular stomatitis and an unevenly spaced beard. On laboratory investigation, he was found to be anaemic ( $\mathrm{Hb} 1 \mathrm{Og} / \mathrm{dl} \mathrm{MCV}$ 65), serum iron.

Upper GI endoscopy showed loss of kerckring folds in the descending duodenum and the histopathology revealed complete villous atrophy. The serology markers were positive for antigliadin, antireticuline and anti-endomysial antibodies. Based on the above findings, the diagnosis of celiac disease was strongly suspected and the patient was managed with glutenfree diet, vitamin and minerals. He responded nicely and all his symptoms and signs improved and he had $35 \mathrm{~kg}$ gain. Repeated duodenal biopsy after one year of the treatment.

\section{Case 2}

A 25-year-old Saudi female was complaining of longstanding anorexia and flatulence. She was seen indifferent health centers and diagnosed as having IBS and managed accordingly with negative response. She described regular deterioration of her symptoms. On physical examination she was pale and depressed, spleen was just palpable and lower limbs edema.

The laboratory investigations revealed anemic patient ( $\mathrm{Hb} 9.5 \mathrm{mg} / \mathrm{dl}$ and $\mathrm{MCV} 65)$. Her serum albumin was on the lower side. Adult celiac disease was entertained in the differential diagnosis. Upper GI endoscopy was performed, duodenal biopsy obtained and histopathology revealed total villous atrophy. The antireticuline and antiendomysial antibodies were positive, but antigliadin antibody was negative. The patient was managed as celiac disease and she responded perfectly. Repeated endoscopy and biopsy after one year showed normalization of her duodenal villi, anemia and weight (she gained $10 \mathrm{~kg}$ ).

\section{Case 3}

This Patient is a 30-year-old Palestinian female, who presented with palpitation and secondary amenorhea. She was seen and evaluated for possible mitral valve prolapse and hyperthyroidism. On examination, she was pale and ill-looking with few aphtous ulcers in her oral cavity. Gynecological examination revealed no abnormalities. Her investigation showed $\mathrm{Hb}$ of $8.8 \mathrm{mg} / \mathrm{dl}$ with iron and folate deficiency and evidence of osteoporoses. Antigliadin and antiendomysial antibodies were positive. Endoscopic duodenal biopsy revealed total villous atrophy._Following the management for adult celiac disease, all her symptoms improved and she regained her periods. Repeated duodenal biopsy and histopathology revealed partial reconstruction of the villous structure.

\section{Discussion}

Since the recognition of celiac disease in the 1950's, it has increasingly been diagnosed in both adults and children. The incidence varies from (1/100 to 1/1500). It has become apparent that 


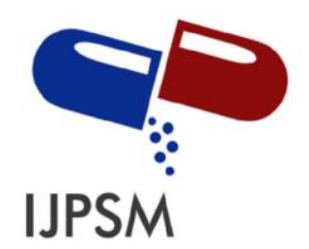

Saloni Chourasia et al, Int. Journal of Pharmaceutical Sciences and Medicine (IJPSM), Vol.6 Issue. 8, August- 2021, pg. 42-72

ISSN: 2519-9889

Impact Factor: 3.426

the prevalence of CD is higher than previously thought, because of an increasing awareness of atypical, mildly symptomatic or silent cases.

This study showed that a typical CD is associated with a wide variety of extra intestinal manifestations, highlighting the association between atypical celiac disease and extra gastrointestinal manfestations including miscarriage infertility and hair fall. Serologic markers (antibody titers to gliadin, reticulin, and endomysial) are known to be raised. in individuals with untreated celiac disease. These titres usually fall on treatment with gluten- free diet. Antiglaidin antibody (AGA) and endomysial tests are the most accurate. A recent study reported the sensitivity of IgG AGAs and IgA AGAs to be $100 \%$ and $89 \%$ respectively in untreated children, the specificity was $86 \%$ for $\operatorname{IgG}$ and $95 \%$ for $\operatorname{IgA}$. Antiendomysial antibodies (EMA) are connective tissue protein found between myofibrils in the gastrointestinal tract of primates. The sensitivity and specificity of EMAs have been reported to be 97-100\% and 98-99\% respectively. Anti tissue transglutaminase antibodies (t TG) is another immunological marker, which are highly sensitive, but less specific than EMA.. Further studies are required to establish the role of isolated anti t TG positivity. Small bowel biopsy remains the gold standard for the diagnosis of glutensensitive enteropathy. Since untreated celiac disease can be life threatening, a combination of clinical suspicion, IgAEMA total IgA Antibody level and small intestinal biopsies are required to identify most cases of atypical or sub clinical celiac disease. However, a more precise description of sub clinical/silent celiac disease can only emerge from screening studies on general population. In conclusion this report and review confirms the presence of $\mathrm{CD}$ in our society and highlights the extremely polymorphic nature of this disease, which can affect any organ. A High index of suspicion is needed to identify the atypical forms of the disease.

\section{Supplements That Are Good for People With Celiac Disease}

People with celiac disease are at risk for nutritional deficiencies because the disease can limit the small intestine's ability to absorb nutrients from food. Your doctor can test for nutritional deficiencies with a simple blood test.

- Assess symptoms and coping skills

- Conduct a dietary review

\section{Long-Term Health Effects}

Celiac disease can develop at any age after people start eating foods or medicines that contain gluten. Left untreated, celiac disease can lead to additional serious health problems.

These include the development of other autoimmune disorders like Type I diabetes and multiple sclerosis (MS), dermatitis herpetiformis (an itchy skin rash), anemia, osteoporosis, 


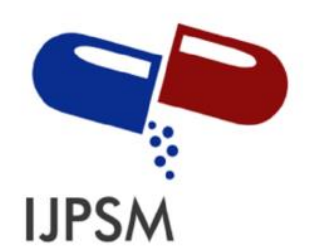

Saloni Chourasia et al, Int. Journal of Pharmaceutical Sciences and Medicine (IJPSM),

Vol.6 Issue. 8, August- 2021, pg. 42-72

ISSN: 2519-9889

Impact Factor: 3.426

infertility and miscarriage, neurological conditions like epilepsy and migraines, short stature, and intestinal cancers.

\section{Treatment}

Currently, the only treatment for celiac disease is lifelong adherence to a strict gluten-free diet. People living gluten-free must avoid foods with wheat, rye and barley, such as bread and beer. Ingesting small amounts of gluten, like crumbs from a cutting board or toaster, can trigger small intestine damage.

Celiac disease is also known as coeliac disease, celiac sprue, non-tropical sprue, and gluten sensitive enteropathy.

A table illustrating how age of diagnosis influences the chances of developing another autoimmune condition

Early Diagnosis Lowers Chance for Developing Another Condition \begin{tabular}{|l|l}
\hline Age of Diagnosis & Chance of developing another autoimmune condition
\end{tabular}

\begin{tabular}{l|l}
\hline $2-4$ & $10.5 \%$
\end{tabular}

\begin{tabular}{l|l}
\hline $4-12$ & $16.7 \%$
\end{tabular}

\begin{tabular}{l|l}
$12-20$ & $27 \%$
\end{tabular}

Over $20 \quad 34 \%$

\section{Undiagnosed or Untreated Celiac Disease Can Lead to: Long-Term Health Conditions}

- Iron deficiency anemia

- Early onset osteoporosis or osteopenia

- Infertility and miscarriage

- Lactose intolerance

- Vitamin and mineral deficiencies

- Central and peripheral nervous system disorders

- Pancreatic insufficiency

- Intestinal lymphomas and other GI cancers (malignancies)

- Gall bladder malfunction

- Neurological manifestations, including ataxia, epileptic seizures, dementia, migraine, neuropathy, myopathy and multifocal leucoencephalopathy.

\section{Other Autoimmune Disorders}

In a 1999 study, Ventura, et al. found that for people with celiac disease, the later the age of diagnosis, the greater the chance of developing another autoimmune disorder. 


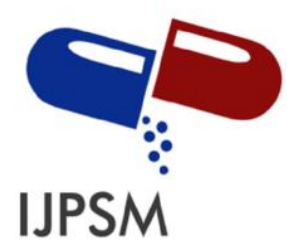

Saloni Chourasia et al, Int. Journal of Pharmaceutical Sciences and Medicine (IJPSM),

Vol.6 Issue. 8, August- 2021, pg. 42-72

ISSN: 2519-9889

Impact Factor: 3.426

Think you or someone you know may have celiac diseases.

\begin{tabular}{|l|l|}
\hline \multicolumn{2}{|l|}{ Autoimmune and Other Conditions Associated with Celiac Disease } \\
\hline Autoimmune Condition & Prevalence in CD Population \\
\hline Anemia & $12-69 \%$ \\
\hline Autoimmune Hepatitis & $2 \%$ \\
\hline Autoimmune Thyroid Disease & $26 \%$ \\
\hline Chronic fatigue syndrome & $2 \%$ \\
\hline Dermatitis Herpetiformis & $25 \%$ \\
\hline Down's syndrome & $12 \%$ \\
\hline Gluten ataxia & $10-12 \%$ \\
\hline Idiopathic Dilated Cardiomyapathy & $5.7 \%$ \\
\hline Juveline Idiopathic Arthritis & $1.5-6.6 \%$ \\
\hline Liver Disease & $10 \%$ \\
\hline Lymphocytic Colitis & $15-27 \%$ \\
\hline Microscopic Colitis & $4 \%$ \\
\hline Peripheral Neuropathy & $10-12 \%$ \\
\hline Primary Bilary Cirrhosis & $3 \%$ \\
\hline Sjögren's Syndrome & $3 \%$ \\
\hline Type 1 Diabetes & $8-10 \%$ \\
\hline Unexplained infertility & $12 \%$ \\
\hline
\end{tabular}

\section{Poorly Responsive Celiac Disease}

It is estimated that up to $30 \%$ of celiac disease patients have persistent symptoms while on the gluten-free diet . The most common reason for persistent symptoms is continuing to ingest gluten.

\section{Causes of Poorly Responsive Celiac Disease Continuing Gluten Ingestion}

The most common reason for persistent symptoms is continuing to ingest gluten, either knowingly or unknowingly. Patients are encouraged to meet with a dietitian knowledgeable about celiac disease and the gluten-free diet to learn about the "hidden" source of gluten. 


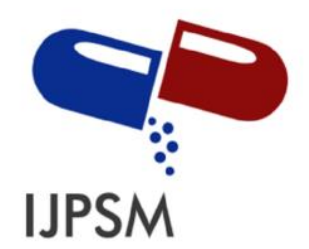

Saloni Chourasia et al, Int. Journal of Pharmaceutical Sciences and Medicine (IJPSM),

Vol.6 Issue. 8, August- 2021, pg. 42-72

ISSN: 2519-9889

Impact Factor: 3.426

\section{Microscopic Colitis, Crohn's Disease and Ulcerative Colitis}

People with celiac disease have an increased incidence of microscopic colitis and inflammatory bowel disease (Crohn's disease and ulcerative colitis). Microscopic colitis is an inflammation of the colon, or large intestine. Crohn's disease is a chronic inflammatory disease of the digestive tract.

Ulcerative colitis is type of inflammatory bowel disease that causes sores in the colon.

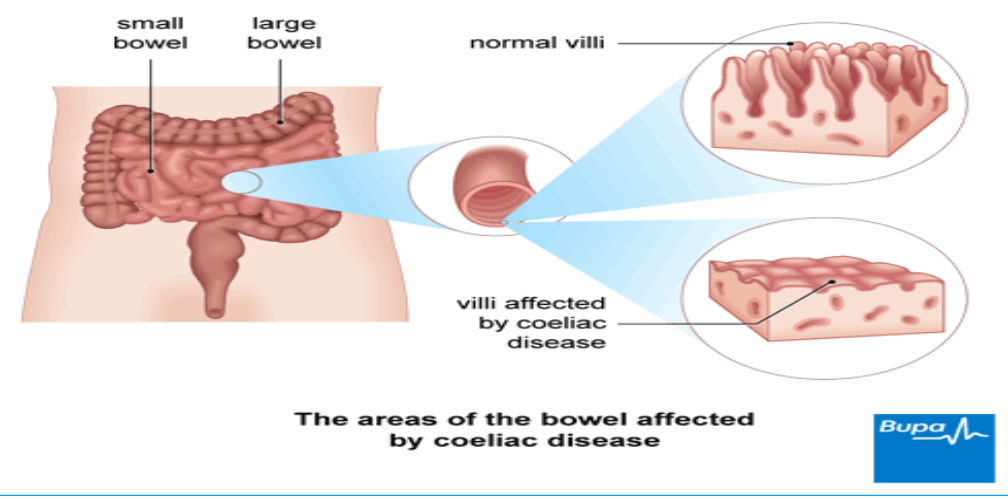

Figure:7 Colonscopy

\section{Small Intestinal Bacterial Overgrowth (SIBO)}

Bacterial overgrowth is a condition in which abnormally large numbers of bacteria are present in the small intestine, while the types of bacteria found in the small intestine are more like the bacteria found in the colon. This is usually diagnosed by a hydrogen breath test.

\section{Pancreatic Insufficiency}

Pancreatic insufficiency is the inability to properly digest food due to a lack of digestive enzymes made by the pancreas. This can be diagnosed by the measurement of enzymes in the stool.

\section{Other Food Intolerances}

People with celiac disease may have lactose or fructose intolerance, both of which can be diagnosed by a hydrogen breath test. Some research has shown that people with lactose or fructose intolerance, and irritable bowel syndrome (IBS), inflammatory bowel disease (Crohn's disease and colitis) benefit from a diet low in FODMAPs (fermentable oligosaccharides, disaccharides, monosaccharides and polyols).

A low FODMAP diet is most effective under the guidance of a skilled, experienced dietitian, who will systematically help you eliminate and reintroduce different categories of the FODMAPs. 


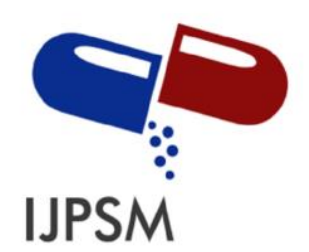

Saloni Chourasia et al, Int. Journal of Pharmaceutical Sciences and Medicine (IJPSM),

Vol.6 Issue. 8, August- 2021, pg. 42-72

ISSN: 2519-9889

Impact Factor: 3.426

\section{Refractory Celiac Disease (or Refractory Sprue)}

Refractory celiac disease, also known as refractory sprue, affects up to $5 \%$ of patients.

For these patients, the damaged villi in the small intestine do not heal from a gluten-free diet, and all other potential causes for this damage have been ruled out. These patients are usually treated with steroids and immunosuppressants.

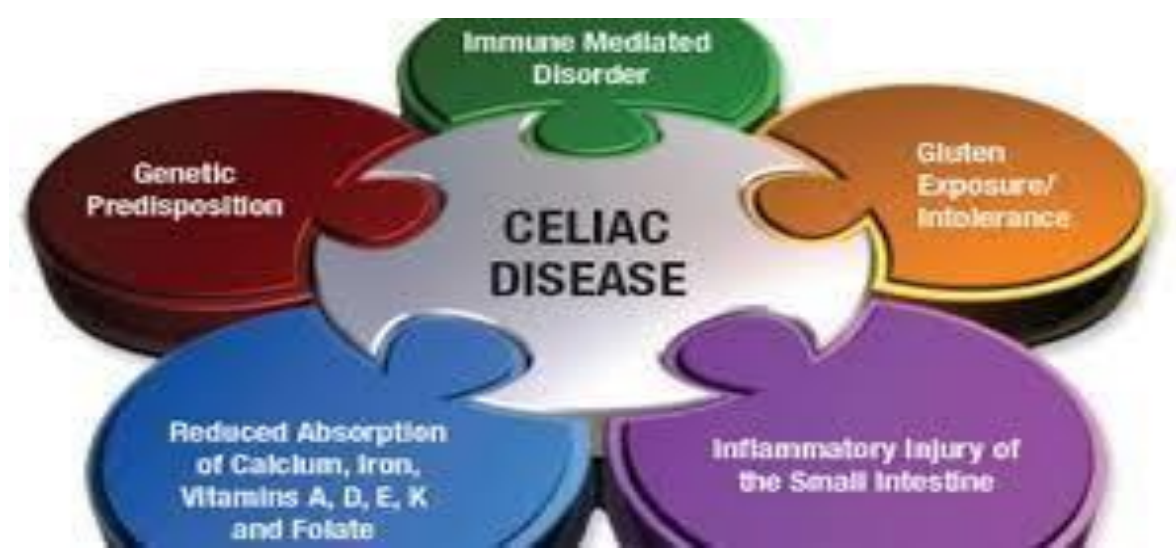

Figure:10 Supplements

Taking a multivitamin or nutritional supplement can help you build your levels of essential nutrients back up.

But keep in mind that some vitamins, minerals, and herbal supplements contain an ingredient called lecithin. Lecithin can be a hidden source of gluten. Talk to your doctor or pharmacist before taking any nutritional supplement to make sure it doesn't contain gluten.

Gluten-free diets are sometimes low in fiber, which can lead to constipation. A fiber supplement with psyllium seed husks can also help, as can fiber-rich foods, like fruits and veggies.

\section{Gluten, Depression, and Anxietv: The Gut-Brain Link}

A small percentage of people with celiac disease find that their symptoms don't improve, even with a strict gluten-free diet.

Symptoms may go away initially but then return, even in the absence of gluten. It's unclear why this happens. Doctors call this refractory celiac disease. If you have refractory celiac Steroids are typically taken for a short period of time to suppress the immune system and stop 


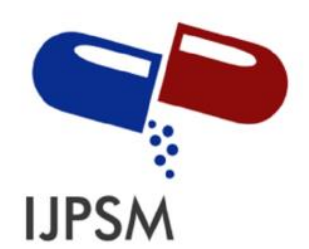

Saloni Chourasia et al, Int. Journal of Pharmaceutical Sciences and Medicine (IJPSM),

Vol.6 Issue. 8, August- 2021, pg. 42-72

ISSN: 2519-9889

Impact Factor: 3.426

the body's harmful immune responsive.

\section{Possible Complications of Untreated Celiac Disease?}

Getting treatment for the disease and changing lifestyle habits, such as following a gluten- free diet, can help prevent long-term complications.

Long-term complications of celiac disease may include:

- Malnutrition

- Anemia (low red blood cell count)

- Osteoporosis (weak bones caused by loss of bone density)

- Infertility or miscarriage

- Certain cancers (intestinal lymphoma, small bowel cancer)

- Lactose intolerance

- Dermatitis herpetiformis (an itchy rash of bumps and blisters) or other skin conditions.

\section{Causes of Food Allergy}

- Milk

- Egg

- Wheat

- Soy

- Peanuts

- Tree nuts

- Fish

- Shellfish

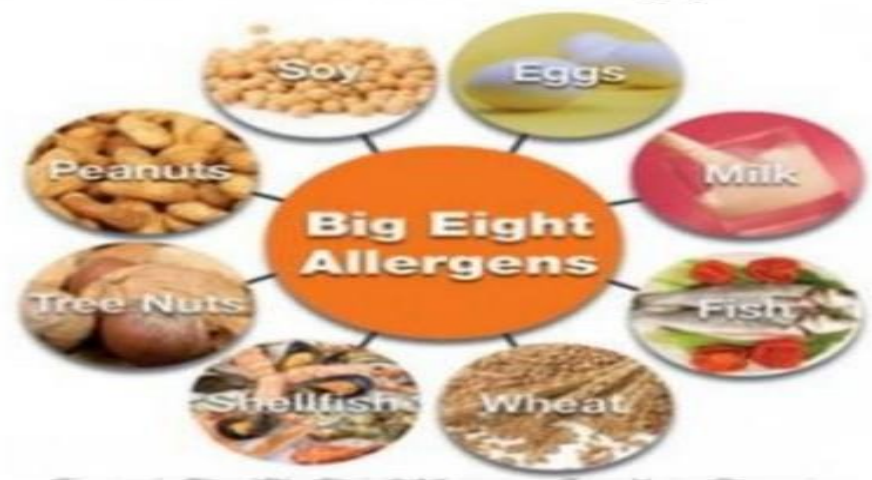

Figure:11 Causes Of Food Allergy

\section{Gluten-Free Diet to Control Celiac Disease}

Gluten is found in many commonly loved foods, including traditional pizza crust, several types of sandwich breads, pasta, tortillas, cake, cookies, and even soy sauce. But for people with celiac disease, knowing the foods and products gluten lurks in and then avoiding them is key for keeping symptoms controlled and preventing an attack.

\section{Foods to Avoid}

Any foods made with wheat, barley, or rye contain some amount of gluten. That means that people with celiac disease shouldn't eat most breakfast cereal, bread, pasta, and processed foods disease, your doctor may prescribe a steroid medication, such as Deltasone (prednisone). 


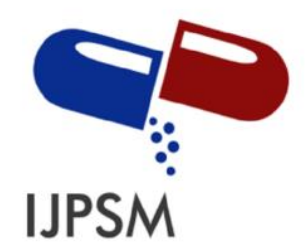

Saloni Chourasia et al, Int. Journal of Pharmaceutical Sciences and Medicine (IJPSM),

Vol.6 Issue. 8, August- 2021, pg. 42-72

ISSN: 2519-9889

Impact Factor: 3.426

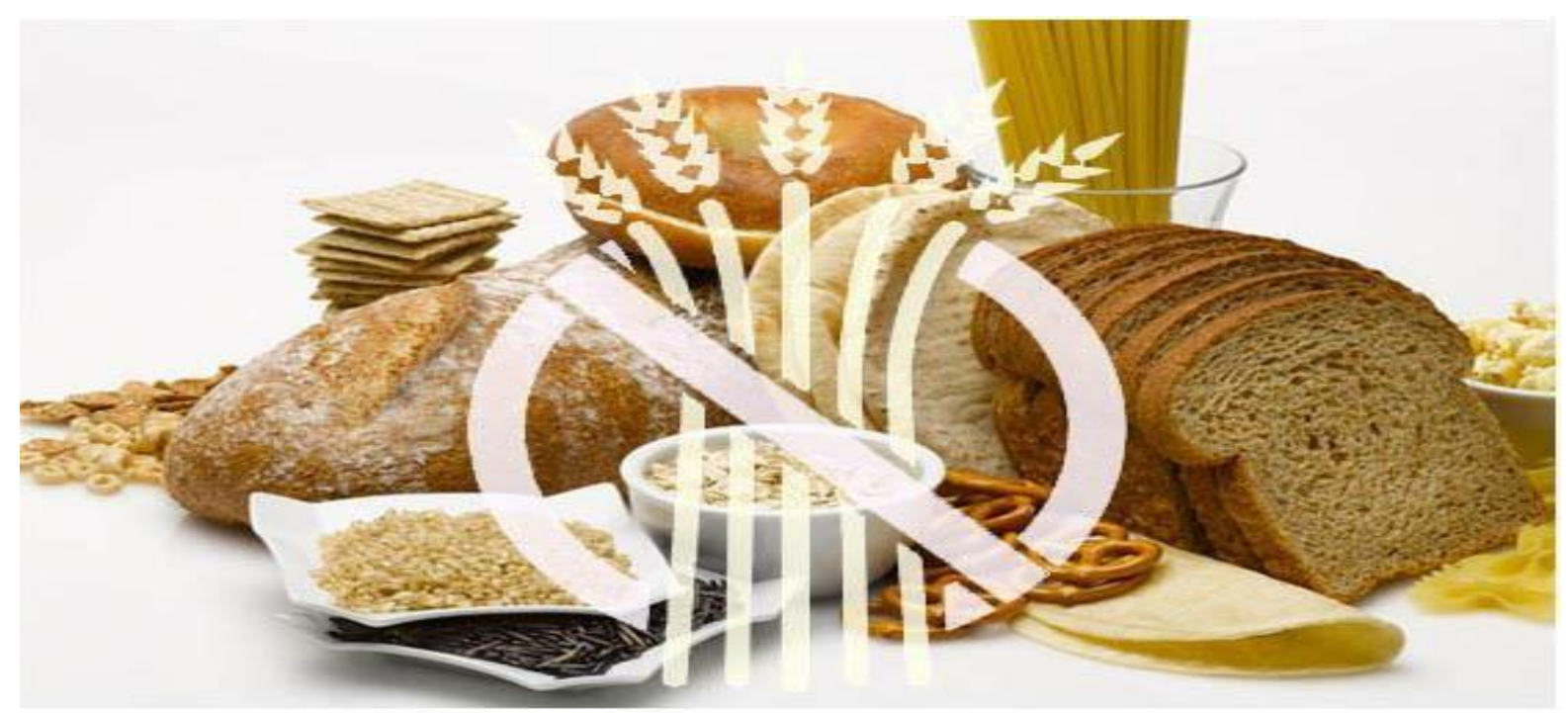

Figure:12 Gluten Avoid Processed foods that may contain gluten include:

- Bouillon cubes

- Brown rice syrup

- Candy

- Chewing gum

- Chips, including seasoned tortilla and potato chips

- Cold cuts, hot dogs, salami, and sausage

- Communion wafers

- French fries

- Gravy

- Imitation fish

- Rice mixes

- Soy sauce

- Beer and malt beverages

Soups and sauces are common sources of hidden gluten, as wheat is often used as a thickener. Pay special attention to sauces or soups that are cream based.

\section{Gluten-Free Foods}

Cutting gluten out of your diet may seem like a difficult task, but many foods are naturally gluten-free. 


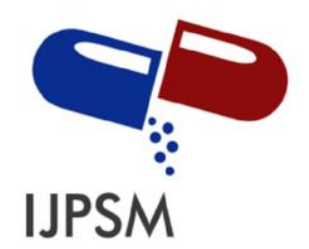

Saloni Chourasia et al, Int. Journal of Pharmaceutical Sciences and Medicine (IJPSM),

Vol.6 Issue. 8, August- 2021, pg. 42-72

ISSN: 2519-9889

Impact Factor: 3.426

In general, the following food groups are naturally gluten-free:

- Fruits

- Vegetables

- Fresh cuts of meat and poultry

- Fish and seafood

- Dairy

- Beans, legumes, and nuts

Beware, though, that prepared or processed versions of any of the above foods, such as sausage or ice cream, may contain gluten.

There are many gluten-free grains and starches that you can substitute for wheat, barley, or rye products:

- Rice

- Corn

- Potato (but not potato chips)

- Tapioca

- Sorghum

- Soy

- Quinoa

- Millet

- Arrowroot

- Amaranth

- Teff

- Flax

- Chia

- Gluten-free oats

- Buckwheat

- Nut flours

Tips for Dining Out on a Gluten-Free Diet

The following strategies may help you stick to your gluten-free diet when eating out:

- Choose a restaurant with gluten-free options. This means picking a place that serves naturally gluten-free foods or has a special gluten-free menu.

- Inform your waiter. Let them know you have celiac disease and may get sick if you eat anything containing gluten, including flour, bread crumbs, or soy sauce. Also ask them to inform the chef or cook. This way, you'll have more confidence that nothing on your plate has touched gluten. 


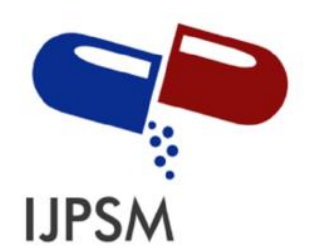

Saloni Chourasia et al, Int. Journal of Pharmaceutical Sciences and Medicine (IJPSM),

Vol.6 Issue. 8, August- 2021, pg. 42-72

ISSN: 2519-9889

Impact Factor: 3.426

- Ask questions. Don't assume anything is gluten-free. Omelets, for instance, may have pancake batter added to the egg mixture to make them fluffier, and baked potatoes can be coated with flour to make the skins brown and crispy.

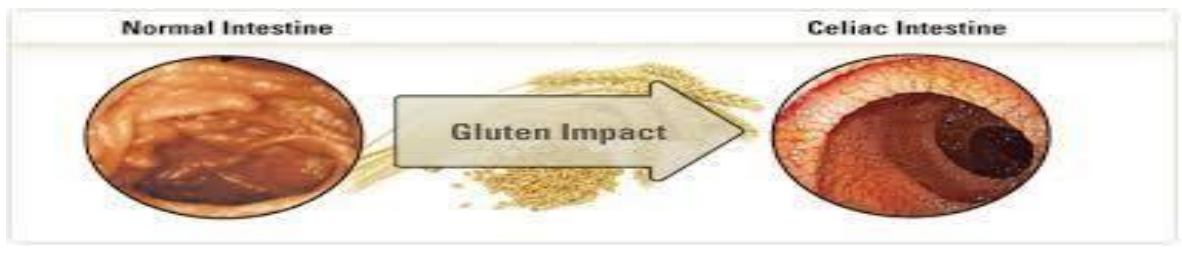

Figure 13: Gluten Impact

\section{References}

[1]. Goldstein NS. Non-gluten sensitivity-related small bowel villous flattening with increased intraepithelial lymphocytes: not all that flattens is celiac sprue. Am J Clin Pathol. 2004.

[2]. Ciclitira PJ. AGA technical review on celiac sprue. Gastroenterology. 2001.

[3]. Abdulkarim AS, Murray JA. The diagnosis of coeliac disease.

[4]. Not T, Horvath K, Hill ID, Partanen J, Hammed A, Magazzu G, Fasano A. Celiac disease risk in the USA.

[5]. Maki M, Mustalahti K, Kokkonen J, Kulmala P, Haapalahti M, Karttunen T, Ilonen J, Laurila K, Dahlbom I, Hansson T, Hopfl P, Knip M. Prevalence of Celiac disease among children in Finland. N Engl J Med. 2003.

[6]. McLoughlin R, Sebastian SS, Qasim A, McNamara D, O'Connor HJ, Buckley M, O'Morain C. Coeliac disease in Europe.

[7]. Dube C, Rostom A, Sy R, Cranney A, Saloojee N, Garritty C, Sampson M, Zhang L, Yazdi F, Mamaladze V, Pan I, MacNeil J, Mack D, Patel D, Moher D. The prevalence of celiac disease in average-risk and at-risk

[8]. Collin P, Reunala T, Rasmussen M, Kyronpalo S, Pehkonen E, Laippala P, Maki M. High incidence and prevalence of adult coeliac disease

[9]. MacDonald WC, Dobbins WO, Rubin CE. Studies on the familial nature of celiac sprue using biopsy of the small intestine. N Engl J Med.

[10]. Auricchio S, Mazzacca G, Tosi R, Visakorpi J, Maki M, Polanco I. Coeliac disease as a familial condition: Identification of asymptomatic coeliac patients within family groups. Gastroenterology Intl. 1988.

[11].Kemppainen T, Kroger H, Janatuinen E, Arnala I, Kosma VM, Pikkarainen P, Julkunen R, Jurvelin J, Alhava E, Uusitupa M. Osteoporosis in adult patients with celiac disease.

[12]. Bossart R, Henry K, Booth CC, Doe WF Subepithelial collagen in intestinal malabsorption. 


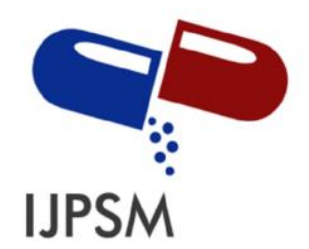

Saloni Chourasia et al, Int. Journal of Pharmaceutical Sciences and Medicine (IJPSM), Vol.6 Issue. 8, August- 2021, pg. 42-72

ISSN: 2519-9889

Impact Factor: 3.426

[13]. Collin P, Maki M. Associated disorders in coeliac disease: clinical aspects. Scand J Gastroenterol. 1994.

[14]. Bottaro G, Cataldo F, Rotolo N, Spina M, Corazza GR. The clinical pattern of subclinical silent celiac disease: An analysis on 1026 consecutive cases. Am J Gastroenterol. 1999.

[15]. Maki M, Holm K, Koskimies S, Hallstrom O, Visakorpi JK. Normal small bowel biopsy followed by coeliac disease. Arch Dis Child. 1990.

[16]. Hogberg L, Laurin P, Falth-Magnusson K, Grant C, Grodzinsky E, Jansson G, Ascher H, Browaldh L, Hammersjo JA, Lindberg E, Myrdal U, Stenhammar L. Oats to children with newly diagnosed coeliac disease: a randomised double blind study. Gut. 2004.

[17]. Peraaho M, Kaukinen K, Mustalahti K, Vuolteenaho N, Maki M, Laippala P, Collin P. Effect of an oats-containing gluten-free diet on symptoms and quality of life in coeliac disease. A randomized study. Scand J Gastroenterol. 2004.

[18]. Walker-Smith JA, Guandalini S, Schmitz J, Shmerling DH, Visakorpi JK. Revised criteria for diagnosis of coeliac disease. Arch Dis Child. 1990.

[19].Lee SK, Lo W, Memeo L, Rotterdam H, Green PHR. Duodenal histology in patients with celiac disease after treatment with a gluten-free diet. Gastrointes Endoscopy. 2003.

[20]. Ventura A, Magazzu G, Greco L. Duration of exposure to gluten and risk for autoimmune disorders in patients with celiac disease. SIGEP Study Group for Autoimmune Disorders in Celiac Disease. Gastroenterology. 1999. 